\title{
TOURISM AND CULTURAL DYNAMICS: AN INTRODUCTION
}

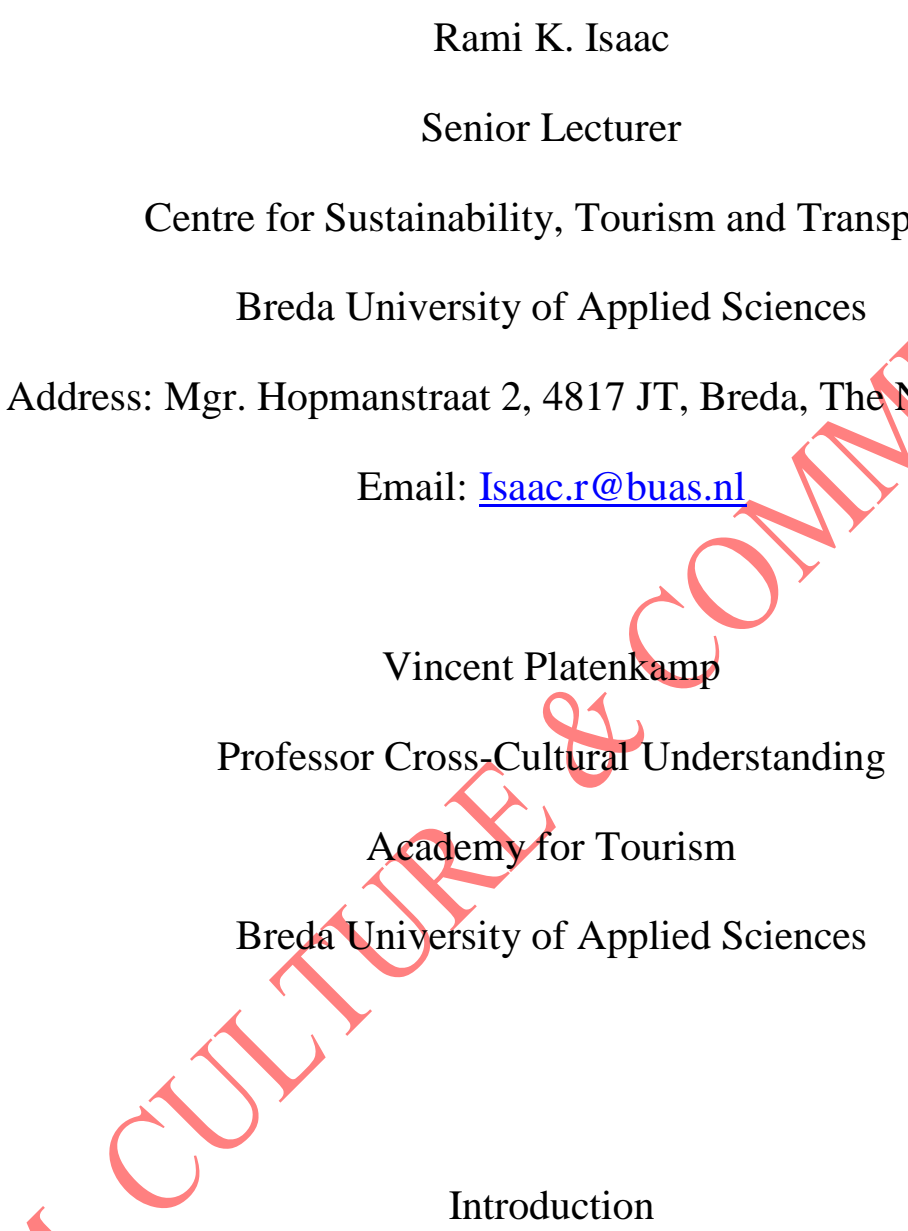

This special issue of Tourism, Culture \& Communication on "Tourism and Cultural Dynamics" was originally conceived of as a point of departure for call for papers based on the in-between conference on tourism and paradoxes organized by the Research Committee 50 (RC50), International Tourism of the International Sociological Association (ISA), in Chiangmai, Thailand in April, 2016. During its course of nearing four decades, tourism studies has covered much disciplinary, thematic and methodological ground. Whilst the field has forged significant practical 
and conceptual benchmarks, international tourism is said to be entering something of a 'new era', and so scholarship in tourism now stands at a philosophical and ethical crossroads. This special issue proposes an opportunity to re-engage with these salient issues in tourism studies and thereby develop possible pathways for its future. By identifying the often unequal and cultural dyads in tourism studies, the special issue aims to consider what is needed, conceptually and methodologically, in order to equip tourism studies to interpret this new era. The present special issue advances conceptual as well as empirical research on cultural dynamics in the context of tourism. The call for papers was encouraged by our research interests in tourism and cultural dynamics. The assemblage of articles in this special issue offers original and advanced international tourism research studies that are entrenched with interdisciplinary and transdisciplinary conceptual and methodological thought in the study of tourism and cultural dynamics. The collection of articles in this special issue represents authors from the Australia, UK, Germany, China, Singapore, Mexico, Afghanistan, The Netherlands and Palestine.

Thinking, according to Deleuze (1976), could best be seen as a rhizome with different ramifications, knots, connections, openings, and hidden places. The most important thinking activity in this rhizome would be the continuous change while creatively and independently drawing nomadic patterns of thought. The more thinking is guided by the free game of creativity, the more its@attractive power.

This metaphor of a rhizome implies an allowance of variegated entrances to the (in our case) social scientific enterprise that are initially as good and as bad as any other one. These diverse entrances imply a prevention to any dominating thought that would eliminate the other entrances. You may enter wherever you want, no entrance has a definite privilege, what changes with the 
choice of an entrance is the map of your route. While you will be walking on different roads, different things will happen on the way.

The least this concept is learning us is the development from Comte's distinction between (social) statics and dynamics to a rhizome of possibly interrelated static and dynamic areas of scientific research that are elaborated in a complicated and often hardly understandable way. One can only hope to un-puzzle the puzzle after having accepted this challenging complexity and try to understand this rhizome.

In this special issue we do not attempt to apply the theoretical insights of Deleuze. His philosophies are not really inviting to organize such an attempt in a direct way. He, himself, would not be interested in such attempts anyway. He allows himself to use and misuse any other theoretical insights to end up with his often intriguing remarks and concepts. In the same way we feel free to (mis)use one of his main, inspiring concepts, the rhizome as point of departure for this special issue on cultural dynamics in the context of tourism. By using the rhizome we welcome as many approaches or entrances as possible, starting from a provocative 'anything goes'. In doing so, we do not select any predominant theoretical position in advance, but challenge any possible alternatives to enter the polyvalent dialogue.

This special issue comprises a series of articles that capture just a glimpse of the types of cutting-edge thinking and academic research in the domain of cultural dynamics in tourism studies. The Guest Editors hope that by reading this special issue academics as well as practitioners will be encouraged to instigate their own studies that will eloquently advance this body of investigation.

Ooi, in his article "Changing Role of Tourism Policy in Singapore's Cultural Dynamics and Development: From Explicit to Insidious". According to Ooi, the disappearance of tourism interests in cultural development stems apparently from years of resistance, dialogues and 
negotiation. He argues that the tourism authorities are still maintaining influence in the cultural dynamics and development of Singapore by reframing its involvement. The article provides a dialogical understanding of how tourism has shaped Singapore's cultural dynamics and that cultural dynamics must be understood within economic and social engineering perimeters defined by the government. Three dialogical concepts were introduced - carnivalesque, heteroglossia and polyphony. His study, in addition, questions on the effectiveness of the arm's length approach to managing cultural development. Singapore's case shows that there are subtle economic and political ways to go round that principle.

Can-Seng Ooi used Bakhtinion Dialogic Imagination to provide a set of lenses to organize and frame the new social complexity. As she puts it on page (19) 'even though this perspective comes from literary studies, the emphasis on order and disorder (carnivalesque), multiple contexts (heteroglossia), and diverse voices (polyphony) has accentuated resistance and compliance by various parties'. From our rhizome point of departure we are most welcome, of course, to this perspective from literary studies.

The second article, focuses the transformation from ethnic cultural representation to place identity. It addresses the complexity and dynamics of maintaining, representing and differentiating identities in bordér territories, which are subject to multiple and heterogeneous mobility flows. The study focuses on Dongxing area, a border city between Guangxi Zhuang Autonomous Regions of China and Vietnam, a multi-ethnic area where Han people have intermarried extensively with other ethnic groups and migrants from surrounding regions. Barth's ethnic boundary theory is employed in her research to unravel tourism, which plays a significant role in maintaining Jing cultural boundaries, based on social interactions. She found that when the representative community has intrinsic strength in terms of economic condition and cultural confidence, the 
challenge for tourist destinations is how to construct a collective identity (or even a brand) to maximize the benefits created by the common activities that all host communities engaged in. Methodological creativity emerges in this article as it does in the article by Min Zhang who tries to understand the transformation processes in a highly heterogeneous community in the border area between China and Vietnam. Rhizomatic thinking challenges exactly this methodological creativity to emerge.

Fagence in his article, also, underlines the importance of pluralist interpretations in his original contribution where he is 'teasing out' what cultural heritage landsoapes and historic sites have 'to say'. As he states in line with Landsberg (2004) 'a parachutist view of history' leads us to an (rhizomatic) organic sort of research as a 'groping exercise' (Moustakas, 1990) with various approaches.

Kuntz, in his article "Battir: Creative Resistance In A Front Line: Opportunities and Dilemmas Of Tourism Development In A Conflict Zone" bring us to the domain of occupation, conflict, non-violent and creative resistance in Battir, Palestine. He reflects on the dynamics that started to appear in Battir, as in spite of tourism development's challenges in a conflict zone, the inhabitants started to react to the UNESCO World Heritage status of village lands and traditional agriculture and offer services to visitors. Since tourism is new to the village, the cultural dynamics unfolding could be influenced by the inhabitants of tourism would be formed consciously beyond the marketing for more visitors. He argues that the amazing story of Hasan Mustafa is an asset for a touristic Battir experience in the framework of a conflict-sensitive tourism. Hasan Mustafa initiated a creative resistance in 1948 and saved the village from destruction. In retelling the motivations, the facts and events of Battir 1948 a tour guide speaks also about creativity, community and opportunities for change. The stories have to be put together to form a reflected 
narrative, which motivates to recognize one's own role in the conflict and the perspectives towards change. Therefore, Palestinian guides can play a decisive role. Battir can be a sample for a tourism development that serves the village as a whole, if methods and ideas of conflict sensitive tourism are applied. In a similar manner as Fagence, Kuntz looks at Battir, a city of creative resistance in a conflict-zone. How does this creativity come into existence under these circumstances, which organic patterns can be distinguished in reaction to his oppressive environment: highly relevant questions for situations where people are struggling for survival and where there is a creative need for many entrances, as rhizomatic thinking would require.

The fifth article of Díaz-Carrión and Vizcaino-Suárez concentrates on tourism and gender in Latin America, with special attention to Brazil and Mexico. In Latin America, tourism gender research was introduced towards the beginning of the $21^{\text {st }}$ century and apart from the limitations identified in the Anglophone academies, the lack of engagement with gender and feminist debates has contributed to marginalize this sub-filed of research. Despite its limitations, tourism gender research in Latin America has made power relations visible in a wide array of tourism practices. Drawing insights from a recent bibliometric analysis of the tourism and gender scholarship in Latin America for the period 2001-2015, this paper focuses on the production of the two leading countries in the region, Brazil and Mexico, and the purpose of the analysis is twofold: First, to identify the main, research topics, and second, to examine the links with feminist or gender frameworks. The findings show that these links are weak, and opportunities were detected to strengthen the association of tourism research with the social sciences through analysis that incorporate cultural and gender dimensions at the macro and micro levels. The author finally, discuss areas of interdisciplinary collaboration with feminist traditions, such as intersectionality and transnationalism that may contribute to advance tourism gender research in the region. 
In this article the authors point, again in this special issue, to the need for richer and more diverse (gender) frameworks in a globalizing world where cultural dynamics comes from everywhere. In their case feminist frameworks offer a dynamic of questions, theories and methods, useful in the analysis of tourism power structures and networks. At the same time Brazilian and Mexican tourism research is in a complex interaction with the Anglo-Saxon ones. Here, there is a set of particular interests to further collaboration in enriching critical studies embedded in global dynamics but also addressing local realities. In search for new entrances, here again, the interconnectivity with inequality, class, ethnicity and others, creates a diyerse field on various levels between the global and the local that is in need of a theoretical and methodological outburst of creative research.

The article written by Su and Cai, entitled "From Cultural Governance to Cultural Tourism: Towards an Interpretation Approach" attempt to address cultural dynamics between symbolism and signification and to demonstrate their relationship within tourism through the studies of cultural governance and cultural tourism. The authors use a case study of cultural tourism in Nanjing, China and illustrate how the tourism and culture sectors selectively signify the tourism image - 'A City of Universal Love' - with Nanjing's cultural governance ideology. Their study offers new insights of cultural dynamics, notably symbolism and signification dynamics that influence governance, interpretation and marketing of the city tourism image.

In this article, the authors, show us that cultural governance moves along well-known tracks between culture and tourism management. These patterns are being questioned, here, and more opened up by choosing a different entrance - in line with rhizomatic thinking - through changing from cultural governance to cultural tourism in an interpretation approach with the inclusion of dissenting voices and the persistent acceptation of cultural diversity. The final article 
by Atai draws from the work of dissonant heritage, and politics in the case of Afghanistan with the bombardment of the Buddhas. Atai attempts to explore the main impulses that might have led to the destruction of Buddha statues by Taliban in the Bamiyan Valley of Afghanistan. This article suggests that the main impulses that have led to the destruction are rather linked to the overall political context of that time (i.e. political iconoclasm) rather than to pure Islamic iconoclasm or an explicit condition of disharmony of heritage (i.e. dissonant heritage). According to the author, the destruction seems a political iconoclasm that is a political exploitation, if not a direct political act. The destruction of Buddha was solely triggered by theological and cultural factors might also be improbable. Attai opens up a new entrance in this article on theldestruction of the Buddha statues by the Taliban in the Bamiyan Valley of Afghanistan. This article investigates the relation of (religious) interpretation with the cold power analysis of political iconoclasm. Were the Taliban motivated by fundamentalist Islam or by political power in its broader context?

Our aim in this special issue is toinspire the tourism academic community in an interesting quest for creative and pluralist interpretations and analyses that are so badly needed in a tourism field where many still seem to think that there is only one entrance to social scientific thinking.

\section{References}

Deleuze, G. (1976) Rhizome introduction. Paris: Les Editions de Minuit.

Landsberg, A. (2004). Prosthetic Memory: the transformation of American remembrance in the age of mass culture. New York: Columbia University Press.

Moustakas, C. (1990). Heuristic Research: design, methodology and applications. Newbury Park: SAGE. 